\title{
An Efficient Numerical Simulation of 2D Natural Convection in an Inclined Cavity with Internal Heat Generation Using Differential Quadrature Method
}

\author{
Israa ALESBE ${ }^{1}$, Sattar ALJABAIR ${ }^{1, *}$ and Jalal M. JALIL ${ }^{2}$ \\ ${ }^{I}$ Department of Mechanical Engineering, University of Technology, Baghdad, Iraq \\ ${ }^{2}$ Electromechanical Engineering Department, University of Technology, Baghdad, Iraq
}

('Corresponding author's e-mail: sattar.j.aljabair@uotechnology.edu.iq)

Received: 28 January 2021, Revised: 1 May 2021, Accepted: 14 May 2021

\begin{abstract}
Natural laminar convective fluid flow has been simulated inside inclined rectangular cavities with and without internal heat generation for different aspect ratios and inclination angles. The most important basic dimensionless parameters for this problem are the external Rayleigh number $\left(\mathrm{Ra}_{\mathrm{E}}\right)$ and the internal Rayleigh number $\left(\mathrm{Ra}_{\mathrm{I}}\right)$, where $\mathrm{Ra}_{\mathrm{E}}$ refers to the effects of the differential heating of the side walls and $\mathrm{Ra}_{\mathrm{I}}$ refers to the amount of heat produced internally. Results were obtained for 4 cases with 192 tests: case (1), $\mathrm{Ra}_{\mathrm{I}}=0$ without internal source generation, and cases $(2,3$, and 4) with internal source generation for $\mathrm{Ra}_{\mathrm{I}}=\mathrm{Ra}_{\mathrm{E}}, 10 \mathrm{Ra}_{\mathrm{E}}$, and $100 \mathrm{Ra}_{\mathrm{E}}$, respectively. In all cases, the parameters of study changed as $10^{3} \leq \mathrm{Ra}_{\mathrm{E}}$ $\leq 10^{6}, 0 \leq \mathrm{Ra}_{\mathrm{I}} \leq 10^{7}$, inclination angle from 0 to $60 \mathrm{deg}$., and aspect ratios of the enclosure from 0.5 to 2 . Results were represented graphically for flow and thermal fields as a streamline, isothermal contours, and Nusselt number. The computed results show that the strength of convection currents is measured by the internal energy. Finally, it is illustrated that by using a few grid points and a shorter CPU time for calculation, the present method can produce accurate numerical results. Also, increase in $R a_{I}$ leads to increasing heat transfer rate and its direction out from the cavity at both hot and cold walls. For lower values of $R a_{I}$, heat transfer diffusion is more prominent, while for higher values of $R a_{I}$, convection outweighs diffusion.
\end{abstract}

Keywords: DQ method, Natural convection, Numerical method, Internal heat generation

\begin{tabular}{|c|c|c|c|}
\hline \multicolumn{4}{|c|}{ Nomenclature } \\
\hline AR & Aspect ratios of the cavity (height/length) & $\mathrm{T}$ & Temperature $\left({ }^{\circ} \mathrm{C}\right)$ \\
\hline \multirow{2}{*}{$A_{i, k}^{(l)}$} & Weighting coefficient for first order & $u, v$ & Dimension and dimensionless velocities \\
\hline & derivatives respect to $\mathrm{X}$ & $U, V$ & in $\mathrm{x}$ and $\mathrm{y}$ directions, respectively \\
\hline \multirow{2}{*}{$B_{j, k}^{(m)}$} & Weighting coefficient for $\mathrm{m}^{\text {th }}$ order & $x, y$ & Dimension and dimensionless Cartesian \\
\hline & derivatives respect to $\mathrm{Y}$ & $X, Y$ & coordinates, respectively \\
\hline g & Gravitational acceleration $\left(\mathrm{m} / \mathrm{s}^{2}\right)$ & \multicolumn{2}{|c|}{ Greek symbols } \\
\hline $\mathrm{L}$ & Number of points in the X-direction & $\gamma$ & Inclination angle (deg.) \\
\hline$L_{X}, L_{Y}$ & Length and height of the cavity (m) & $\tau$ & Dimensionless time increment \\
\hline $\mathrm{M}$ & Number of grid points in the $\mathrm{Y}$-direction & $\alpha$ & Diffusivity $\left(\mathrm{m}^{2} / \mathrm{s}\right)$ \\
\hline$N u_{o}$ & Average Nusselt number at $X=0$ & $\beta$ & Coefficient of thermal expansion $(1 / \mathrm{K})$ \\
\hline$N u_{\text {avg }}$ & $\begin{array}{l}\text { Average Nusselt number through the whole } \\
\text { cavity }\end{array}$ & $v$ & Kinematic viscosity $\left(\mathrm{m}^{2} / \mathrm{s}\right)$ \\
\hline$N u_{\text {local }}$ & $\begin{array}{l}\text { Average Nusselt number on vertical lines in } \\
\text { the cavity }\end{array}$ & $\theta$ & Dimensionless temperature \\
\hline $\operatorname{Pr}$ & Prandtl number & $\psi, \Psi$ & Dimension and dimensionless stream \\
\hline
\end{tabular}




$\begin{array}{ll}\mathrm{Q} & \text { Internal volumetric heat generation } \\ \mathrm{Ra} & \text { Rayleigh number } \\ R a_{E} & \text { External Rayleigh number } \\ R a_{I} & \text { Internal Rayleigh number } \\ \mathrm{t} & \text { Time (sec) }\end{array}$

functions, respectively

$\rho \quad$ Fluid density $\left(\mathrm{kg} / \mathrm{m}^{3}\right)$

Subscript

c Cold wall

h Hot wall

\section{Introduction}

Within the last decades, convection problems in cavities which are combined with internal or external heating have attracted much interest from researchers. The internal flow, according to the natural convection inside cavities, is particularly complex because of the interaction between the thermal boundary layer (near the cavity walls) and other fluid parts, where it has been studied numerically and experimentally due to various practical applications [1-6]. According to previous studies, natural convection that is combined with internal or external heating has many applications, such as solar energy collection- Singh and Eames [7], building and ventilation- DeBlois et al. [8], cooling of electronic equipment- Bairi et al. [9], and nuclear reactors- Tseng et al. [10], and in many other applications. The differential quadrature DQ method was developed by Bellman et al. [11] for the derivation of an approximate of a smooth function. The DQ method is inspired from the integral quadrature; it approximates the derivative at a mesh point by a weighted sum of all functional values across the entire domain. Obviously, the key to this method is the determination of weighting coefficients. It was found that the computation of the weighting coefficients depends on the approximation of the function. When the function is approximated by a higher order polynomial, Shu and Richards [12] presented some simple algebraic formulations and a recurrence relationship to calculate the weighting coefficients of the $1^{\text {st }}$ and higher order derivatives. For simplicity, this case is called the polynomial-based differential quadrature (PDQ). The researcher's goal is to find an effective approach for obtaining correct numerical results with just a few grid points. The DQ method is the best to achieve very accurate results using a few grid points with less meshing, computational effort, and virtual storage. The details of the DQ method can be found in the book of Shu [13]. Lo et al. [14] proposed a novel numerical solution algorithm based on a differential quadrature method to simulate natural convection in an inclined cubic cavity using a velocityvorticity form of the Navier-Stokes equations. This present algorithm is regarded as an effective method to resolve non-linearity in combination with the vorticity transport equations and the energy equation. The case study uses an inclined cavity which has a different inclination angle and a Rayleigh number equalling $10^{3}$ to $10^{6}$. Lo et al. [15] generalized differential quadrature method to solve the natural convection in a differentially heated cubic enclosure. The mesh in dependence study shows that the numerical procedure needs more coarse mesh compared to other numerical schemes to find the benchmark solutions of the flow and heat transfer problems. The above literature is limited for the DQ method and its application in the engineering field.

Rahman and Sharif [16] investigated free convection laminar flow with or without internal heat generation $R a_{E}=R a_{I}=2 \times 10^{5}$ in a rectangular cavity for various aspect ratios and different angles of inclination. Numerical calculation was presented for a range of cavity aspect ratios from ( 0.25 to 4$)$, the inclination angle changing from $15^{\circ}$ to $90^{\circ}$ for fixed external Rayleigh number, and different internal Rayleigh number. Oztop and Bilgen [17] studied the heated portion in a square cavity with heat source numerically, where the vertical walls were assumed to be isothermal, the horizontal walls were adiabatic, and the bottom wall was attached to the isothermal cold partition. The heat Rayleigh numbers varied from $10^{3}$ to $10^{6}$. They observed 2 distinct flow regimes based on the ratio $R a_{E} / R a_{I}$.

Boukendil et al. [18] studied a numerical laminar natural convective heat transfer and surface radiation around 2 square isothermal cylinders held at different temperatures. These cylinders were contained inside a square cavity with adiabatic walls. The control volume and discrete ordinate methods were used to solve the governing equations iteratively. The results showed that, generally at high Rayleigh numbers, surface radiation has a significant impact on the flow structure in the annulus. The 
http://wjst.wu.ac.th

effect of the inner square cylinders' positions, sides-ratios, and sizes on radiative and convective heat transfers was discovered to be important. In corrugated annuli filled with nanofluid, a numerical natural convection heat transfer was investigated by Aljabair et al. [19]. Eight mathematical models with an aspect ratio of 1.5 were used to find the best model with the highest heat transfer rates. The results showed that increasing the volume fraction of nanoparticles and the Rayleigh number increases the heat transfer rate significantly. Increases in the undulation number increase the activity of the heated surface. Furthermore, heat transfer rates are typically higher in unsymmetrical annuli than in symmetrical annuli. In a cubical cavity with differently heated opposed walls, the laminar and turbulent heat transfer in enclosed domains uses buoyancy-driven flow, presented by Fabregat et al. [20]. This form of arrangement encapsulates the fundamental physics of flows in which the presence of boundary layers regulates the flow near a wall surface. The near-wall flow is characterized as a result, allowing new semi-analytical models for wall transfer applications in enclosed cavities to be created. Hidki et al. [21] exhibited analysis of laminar natural convection in a cavity. Two cylinders of the same surface, but different geometric shapes, were contained inside this cavity (square, circular, and elliptical). Two Rayleigh numbers reflected the uniform volume powers produced by these 2 cylinders; the right wall was cooled with a constant temperature, while the remaining walls were assumed adiabatic. The results demonstrate that Rayleigh numbers have a major impact on cavity flow and heat transfer. El-Dib and Moatimid [22] used coupling and homotopy perturbation method, and Laplace transform was adopted to obtain an approximate solution of the equation of motion. Also, they investigated the governed perturbed solutions, as well as the stability configuration.

Finally, the DQ method is a numerical discretization method that is applied globally. The DQ method has the advantage of being able to produce extremely accurate results with a relatively limited number of grid points and requires very little computational reporting. The DQ approach, like traditional low order finite difference schemes, involves a regular computational domain. The coordinate transformation technique can be used for problems with irregular domains. The aim of this paper is to adopt the differential quadrature method in natural convection and entropy generation applications and show how it can be used to solve the steady state 2-dimensional convection-diffusion equation. The results showed that, using just a few grid points, a high-accuracy numerical solution could be obtained. Compared to some numerical methods developed by researchers in previous studies, it needs less storage and computational effort.

\section{Materials and methods}

\section{Method methodology}

The DQ method produces a set of algebraic equations by changing a given spatial derivative of a function of $\mathrm{f}(\mathrm{x})$ from a linear weighted sum of the function values at discrete sample points computed along a coordinate's direction. This method solves the partial differential equations numerically with higher order accuracy. All the details of and information about the method can be found in Shu [13]. The $1^{\text {st }}$ order derivatives and $\mathrm{m}^{\text {th }}$ order derivatives of a function of 2 variables $\mathrm{f}(\mathrm{x}, \mathrm{y})$ with respect to the $\mathrm{x}$ and $\mathrm{y}$ coordinates can be found as:

$$
\begin{aligned}
& f_{x}^{(l)}\left(x_{i}, y_{j}\right)=\sum_{k=1}^{L} A_{i, k}^{(l)} f\left(x_{k}, y_{j}\right) \\
& f_{y}^{(m)}\left(x_{i}, y_{j}\right)=\sum_{k=1}^{M} B_{j, k}^{(m)} f\left(x_{i}, y_{k}\right) \\
& \text { For } \quad l=1,2 \text {, to }, L-1, \quad m=1,2, \text { to }, M-1 \quad: \quad i=1,2, \text { to }, L, \quad j=1,2 \text {, to , } M
\end{aligned}
$$

where $l$ and $\mathrm{m}$ refers to the points in the $\mathrm{x}$ and $\mathrm{y}$ coordinates, respectively. $\mathrm{L}$ and $\mathrm{M}$ are the grid points numbers in the $\mathrm{x}$ and y coordinates, respectively, and $A_{i, k}^{(l)}$ and $B_{j, k}^{(m)}$ are the weighting coefficients. The $1^{\text {st }}$ order weighting coefficients $A_{i, k}^{(1)}$ and $B_{j, k}^{(1)}$ can be determined as follows:

$A_{i, j}^{(1)}=\frac{L^{(1)}\left(x_{i}\right)}{\left(x_{i}-x_{j}\right) L^{(1)}\left(x_{j}\right)}, i, j=1,2$, to,$L$ but $j \neq i$ 
$B_{i, j}^{(1)}=\frac{M^{(1)}\left(y_{i}\right)}{\left(y_{i}-y_{j}\right) L^{(1)}\left(y_{j}\right)}, i, j=1$, to,$M$, but $j \neq i$

In which

$$
\begin{aligned}
& L^{(1)}\left(x_{i}\right)=\prod_{j=1, j \neq i}^{L}\left(x_{i}-x_{j}\right) \\
& M^{(1)}\left(y_{i}\right)=\prod_{j=1, j \neq i}^{M}\left(y_{i}-y_{j}\right)
\end{aligned}
$$

The weighting coefficients for the $2^{\text {nd }}$ and high order derivatives are calculated similarly:

$A_{i, j}^{(l)}=l\left(A_{i, i}^{(l-1)} A_{i, j}^{(1)}-\frac{A_{i, j}^{(l-1)}}{x_{i}-x_{j}}\right)$

For $i, j=1,2, \ldots, L$ b $j \neq i, l=2,3, \ldots, L-1$

And, $B_{i, j}^{(m)}=m\left(B_{i, i}^{(m-1)} B_{i, j}^{(1)}-\frac{B_{i, j}^{(m-1)}}{y_{i}-y_{j}}\right)$

For $i, j=1,2, \ldots, M$ but $j \neq i, m=2,3, \ldots, M-1$

For $j, i$ the coefficients of weighting are defined as:

$A_{i, i}^{(l)}=-\sum_{j=1, j \neq i}^{L} A_{i, j}^{(l)}$

$i=1,2, \ldots, L-1,=1,2, \ldots, L-1$

$B_{i, i}^{(m)}=-\sum_{j=1, j \neq i}^{M} B_{i, j}^{(m)}$

$i=1,2, \ldots, M-1, m=1,2, \ldots, M-1$

It is very important to know that the $2^{\text {nd }}$ and higher derivative weighting coefficients can be obtained from the order derivatives themselves.

\section{Problem definition and mathematical models}

The geometry of the case study is shown in Figure 1, where the coordinates system and boundary conditions are present. The used model consists of a rectangular cavity; the temperature on the left wall is fixed at $T_{h}$, while the right wall is held at a temperature $T_{c}$, and the top and bottom walls are kept adiabatic. Within the cavity, a regular heat-generating fluid with a volumetric rate has been filled. The thermal flow is characterized by external Rayleigh number $R a_{E}=\beta g\left(T_{h}-T_{c}\right) L_{x}^{3} /(\alpha v)$, Prandtl number $\operatorname{Pr}=v / \alpha$, and internal Rayleigh number $R a_{I}=\beta g Q L_{x}^{3} /(\alpha v)$. The flow is laminar (viscous dissipation is negligible), where the fluid is assumed to be Newtonian and incompressible. The Boussinesq approximation is related with fluid properties; this means it is affected by density changes which depend on temperature changes. The aim of this study is to examine and analyze the result flow from the above assumption and a case study using an efficient numerical method for which preferable convection heat transfer is collected by using the combined effects of $R a_{E}$ and $R a_{I}$.

The steady natural convection governing equations can be expressed in the dimensionless stream function-vorticity form as:

$\nabla^{2} \Psi=-\Omega$

$\Omega_{\tau}+U \Omega_{X}+V \Omega_{Y}=\operatorname{Pr} \nabla^{2} \Omega+\operatorname{Ra}_{\mathrm{E}} \operatorname{Pr}\left(\theta_{\mathrm{X}} \cos \gamma-\theta_{\mathrm{Y}} \sin \gamma\right)$

$\theta_{\tau}+U \theta_{X}+V \theta_{Y}=\nabla^{2} \theta+\mathrm{Ra}_{\mathrm{I}} / \mathrm{Ra}_{\mathrm{E}}$ 
where the dimensionless parameters are:

$X=\frac{x}{L_{x}}, Y=\frac{y}{L_{x}}, U=\frac{u L_{x}}{\alpha}, V=\frac{u L_{x}}{\alpha}, \tau=\frac{t \alpha}{L_{x}^{2}}, \quad \Psi=\frac{\psi}{\alpha}, \quad \theta=\frac{T-T_{c}}{T_{h}-T_{C}}$

Where all parameters appearing in the above equations are given in the nomenclature list.

\section{Formation by DQ method}

The 3 governing Eqs. (6A), (6B), and (6C) can be discretized using the DQ method as [13]:

$$
\begin{aligned}
& \sum_{k=1}^{L} A_{i, k}^{(2)} \cdot \Psi_{k, j}+\sum_{k=1}^{M} B_{j, k}^{(2)} \cdot \Psi_{i, k}=\Omega_{i, j} \\
& \frac{d \Omega_{i, j}}{d \tau}+U_{i, j} \cdot \sum_{k=1}^{L} A_{i, k}^{(1)} \cdot \Omega_{k, j}+V_{i, j} \cdot \sum_{k=1}^{M} B_{j, k}^{(1)} \cdot \Omega_{i, k} \\
& =\operatorname{Pr}\left[\sum_{k=1}^{L} A_{i, k}^{(2)} \cdot \Omega_{k, j}+\sum_{k=1}^{M} B_{j, k}^{(2)} \cdot \Omega_{i, k}\right]+R a_{E} \\
& \cdot \operatorname{Pr}\left[\cos \gamma \cdot \sum_{k=1}^{L} A_{i, k}^{(1)} \cdot \theta_{k, j}-\sin \gamma \cdot \sum_{k=1}^{M} B_{j, k}^{(1)} \cdot \theta_{i, k}\right] \\
& \frac{d \theta_{i, j}}{d \tau}+U_{i, j} \cdot \sum_{k=1}^{L} A_{i, k}^{(1)} \cdot \theta_{k, j}+V_{i, j} \cdot \sum_{k=1}^{M} B_{j, k}^{(1)} \cdot \theta_{i, k}= \\
& {\left[\sum_{k=1}^{L} A_{i, k}^{(2)} \cdot \theta_{k, j}+\sum_{k=1}^{M} B_{j, k}^{(2)} \cdot \theta_{i, k}\right]+\mathrm{Ra}_{\mathrm{I}} / \mathrm{Ra}_{\mathrm{E}}}
\end{aligned}
$$

\section{Boundary conditions implementation}

Table 1 shows the boundary conditions that take place in the domain, while the physical domain is as shown in Figure 1.

Table 1 Boundary conditions.

\begin{tabular}{lllc}
\hline & $\boldsymbol{U}$ & $\boldsymbol{V}$ & $\boldsymbol{\theta}$ \\
\hline Top wall & 0 & 0 & $\partial \theta / \partial Y=0$ \\
Bottom wall & 0 & 0 & $\partial \theta / \partial Y=0$ \\
Left wall & 0 & 0 & 1 \\
Right wall & 0 & 0 & 0 \\
\hline
\end{tabular}

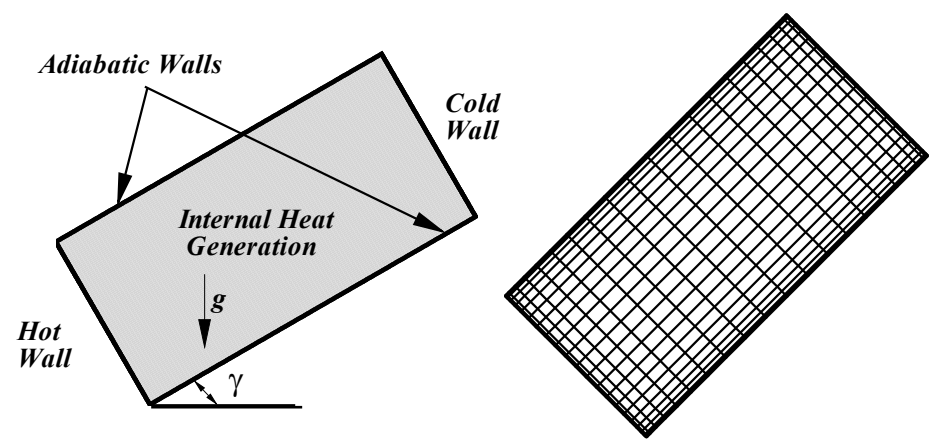

Figure 1 The geometry of the inclined cavity left side and a grid generation in this study, $21 \times 21$ on the right side. 
$U=V=0, \theta=1$, at $X=0,0 \leq Y \geq L_{Y} / L_{X}$

$U=V=0, \theta=0$, at $X=1,0 \leq Y \geq L_{Y} / L_{X}$

$U=V=0, \partial \theta / \partial Y=0$

at $Y=0$, and $Y=L_{Y} / L_{X}$, for $0 \leq X \geq 1$

Where $U=\partial \Psi / \partial \mathrm{Y}, V=-\partial \Psi / \partial \mathrm{X}$

$\Psi=0$. On each boundary (Dirichlet boundary) according to (8D), the 2 velocity components $\mathrm{U}$ and $\mathrm{V}$ boundary conditions can be described by using the stream function, as below:

$\Psi=\partial \Psi / \partial \mathrm{X}=0$. at $X=0,1$ for $0 \leq Y \leq L_{Y} / L_{X}$

$\Psi=\partial \Psi / \partial Y=0$. at $Y=0, L_{Y} / L_{X}$ for $0 \leq X \leq 1$

Also, the derivatives of the boundary conditions can be discretized using the DQ method. By using (6A) with the boundary conditions of (9), an expression for the vorticity boundary condition can be obtained:

$\Omega=\partial^{2} \Psi / \partial X^{2}$, at $X=0,1$ for $0 \leq Y \leq L_{Y} / L_{X}$

$\Omega=\partial^{2} \Psi / \partial Y^{2}$, at $Y=0, L_{Y} / L_{X}$ for $0 \leq X \leq 1$

Now, Eq. (10) can lead to 4 boundaries:

$\Omega_{1, j}=\sum_{k=1}^{L} A_{1, k}^{(2)} \cdot \Psi_{k, j}$, for $j=1,2$, to , $M$

$\Omega_{L, j}=\sum_{k=1}^{L} A_{L, k}^{(2)} \cdot \Psi_{k, j}$, for $j=1,2$, to , $M$

$\Omega_{i, 1}=\sum_{k=1}^{M} B_{1, k}^{(2)} \cdot \Psi_{i, k}$, for $i=2,3$, to , $L-1$

$\Omega_{i, M}=\sum_{k=1}^{M} B_{M, k}^{(2)} \cdot \Psi_{i, k}$, for $i=2,3$, to , $L-1$

where $i=1$ is the left boundary and $i=\mathrm{L}$ for the right one, while $j=1$ and $j=\mathrm{M}$ are for the bottom and top boundaries, respectively. For stream function boundary condition, there are 2 boundaries. The $1^{\text {st }}$ layer condition (Dirichlet condition) at all boundary points is obtained by applying (8E), and Neumann condition using (9) is discretized and combined to create conditions for the $2^{\text {nd }}$ layer (2-layer approach). Appling Neumann condition can give:

$A_{1,2}^{(1)} \cdot \Psi_{2, j}+\sum_{k=1, k \neq 2, L-1}^{L} A_{1, k}^{(1)} \cdot \Psi_{k, j} A_{1, L-1}^{(1)} \cdot \Psi_{L-1, j}=0$

For $\mathrm{X}=0$

$A_{L, 2}^{(1)} \cdot \Psi_{2, j}+\sum_{k=1, k \neq 2, L-1}^{L} A_{L, k}^{(1)} \cdot \Psi_{k, j}+A_{L, L-1}^{(1)} \cdot \Psi_{L-1, j}=0$

For $\mathrm{X}=1$

$B_{1,2}^{(1)} \cdot \Psi_{i, 2}+\sum_{k=1, k \neq 2, M-1}^{M} B_{1, k}^{(1)} \cdot \Psi_{i, k}+B_{1, M-1}^{(1)} \cdot \Psi_{i, M-1}=0$

For $\mathrm{Y}=0$

$B_{M, 2}^{(1)} \cdot \Psi_{i, 2}+\sum_{k=1, k \neq 2, M-1}^{M} B_{M, k}^{(1)} \cdot \Psi_{i, k}+B_{M, M-1}^{(1)} \cdot \Psi_{i, M-1}=0$

For $\mathrm{Y}=1$

Then, by substituting (8E) for (12A) and (12B), we get:

$\Psi_{2, j}=\frac{1}{A X N} \cdot\left[\sum_{k=3}^{L-2}\left(A_{1, k}^{(1)} \cdot A_{L, L-1}^{(1)}-A_{L, k}^{(1)} \cdot A_{1, L-1}^{(1)}\right) \cdot \Psi_{k, j}\right]$ 
$\Psi_{L-1, j}=\frac{1}{A X N} \cdot\left[\sum_{k=3}^{L-2}\left(A_{L, k}^{(1)} \cdot A_{1,2}^{(1)}-A_{1, k}^{(1)} \cdot A_{L, 2}^{(1)}\right) \quad \cdot \Psi_{k, j}\right]$

For $\mathrm{j}=2,3, \ldots . ., \mathrm{M}-1$, where

$A X N=A_{L, 2}^{(1)} \cdot A_{1, L-1}^{(1)}-A_{1,2}^{(1)} \cdot A_{L, L-1}^{(1)}$

Similarly, substituting Eq. (8E) into Eqs. (12C) and (12D) gives:

$\Psi_{i, 2}=\frac{1}{A Y N} \cdot\left[\sum_{k=3}^{M-2}\left(B_{1, k}^{(1)} \cdot B_{M, M-1}^{(1)}-B_{M, k}^{(1)} \cdot B_{1, M-1}^{(1)}\right) \cdot \Psi_{i, k}\right]$

$\Psi_{i, M-1}=\frac{1}{A Y N} \cdot\left[\sum_{k=3}^{M-2}\left(B_{M, k}^{(1)} \cdot B_{1,2}^{(1)}-B_{1, k}^{(1)} \cdot B_{M, 2}^{(1)}\right) \cdot \Psi_{i, k}\right]$

For $i=2,3$, to, L-1, where

$A Y N=B_{M, 2}^{(1)} \cdot B_{1, M-1}^{(1)}-B_{1,2}^{(1)} \cdot B_{M, M-1}^{(1)}$

A layer adjacent to the boundary is solved by using (13); it is mentioned that, when this procedure is used, (7A) can only be used for the internal points $3 \leq i \leq L-2,3 \leq j \leq M-2$. This approach has been successfully applied by Shu and Richards [12] to generate accurate DQ solutions. With the same procedure, the boundary conditions for temperatures along the walls can be discretized, as shown below:

$\theta_{1, j}=1 ., \theta_{L, j}=0$ for $j=1,2, \ldots, M$

The derivative conditions for $\theta$ at $\mathrm{Y}=0$ and $\mathrm{Y}=1$ are discretized using the DQ method and then combined to give:

$\theta_{i, 1}=\frac{1}{A Y T} \cdot\left[\sum_{k=2}^{M-1}\left(B_{1, k}^{(1)} \cdot B_{M, M}^{(1)}-B_{M, k}^{(1)} \cdot B_{1, M}^{(1)}\right) \cdot \theta_{i, k}\right]$

$\theta_{i, M}=\frac{1}{A Y T} \cdot\left[\sum_{k=2}^{M-1}\left(B_{M, k}^{(1)} \cdot B_{1,1}^{(1)}-B_{1, k}^{(1)} \cdot B_{M, 1}^{(1)}\right) \cdot \theta_{i, k}\right]$

$(14 \mathrm{C})$

For $\mathrm{i}=2,3$ to $\mathrm{L}-1$, where

$A Y T=B_{M, 1}^{(1)} \cdot B_{1, M}^{(1)}-B_{1,1}^{(1)} \cdot B_{M, M}^{(1)}$

It should be observed that there is only 1 condition for each boundary point for $\theta$. Therefore, Eq. (6C) is applied for all internal points, $2 \leq i \leq L-1,2 \leq j \leq M-1$.

- The Nusselt number represents the important factor for natural convection.

- The Nusselt number on the left wall and the average Nusselt number throughout the cavity are evaluated as: $N u_{o}=\int_{0}^{L_{Y} / L_{X}} \frac{\partial \theta}{\partial X} d Y, \quad N u_{\text {avg }}=\frac{1}{L_{Y} / L_{X}} \int_{0}^{1} N u_{o} d X$

The average Nusselt number is determined using Lagrange interpolation from a fine mesh, and the integrals according to the above equations are estimated using the trapezoidal law.

\section{Solution procedures}

Numerical solution procedures for the present study can briefly be shown as in Figure 2. The solution procedure starts with a step where the number of grid and convergence threshold should be input to the code. The $1^{\text {st }}$ step for the calculation is mesh generation, where the coordinates of each cell and DQ weighting coefficients are calculated. After that, (7A) is solved by LU decomposition, the matrix is formed and then the LU decomposition performed. The results are matrices [L] and [U], which are stored for subsequent application. The previous steps can give an initial guess of the flow field since the governing equations are nonlinear. The next steps are solving the vorticity $(7 \mathrm{~B})$, solving the stream function (7A), calculating the components of velocity from (8D), solving for the temperature from (7C), and updating the boundary conditions for $\Omega, \Psi$. and $\theta$. 
http://wjst.wu.ac.th

Finally, the convergence criteria should be checked; when they are satisfied, the computation will stop and the results are printed. Otherwise, new results are used as an initial boundary and the calculation is repeated.

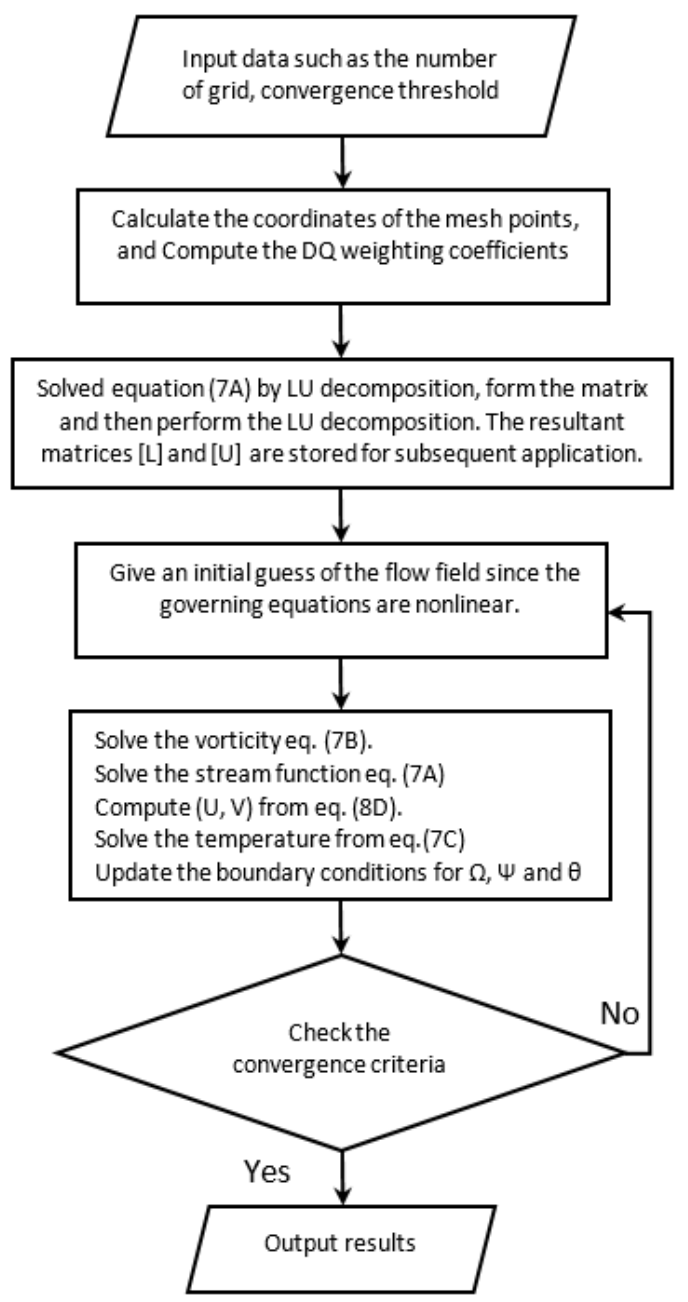

Figure 2 Flow chart of the numerical solution procedure.

The mesh point coordinates can be expressed as [13]:

$X_{i}=\frac{\cos \left[\frac{\pi}{2 L}\right]-\cos \left[\frac{(2 i-1) \pi}{2 L}\right]}{\cos \left[\frac{\pi}{2 L}\right]-\cos \left[\frac{(2 L-1) \pi}{2 L}\right]} \cdot L_{X} \quad ; \quad Y_{j}=\frac{\cos \left[\frac{\pi}{2 M}\right]-\cos \left[\frac{(2 j-1) \pi}{2 M}\right]}{\cos \left[\frac{\pi}{2 M}\right]-\cos \left[\frac{(2 M-1) \pi}{2 M}\right]} \cdot L_{Y}$

where $i=1,2$, to $L ; j=1,2$ to $M$

The convergence criteria in this study can be shown as the below equation:

Relative error $=\operatorname{err}(f, i, j)=\left|\frac{f_{(i, j)}^{n+1}-f_{(i, j)}^{n}}{f_{(i, j)}^{n}}\right|$ 
http://wjst.wu.ac.th

where $\mathrm{n}$ symbolizes the time level, $\mathrm{f}$ is a flow variable, which can be the $\Omega, \Psi$. and $\theta$. With (15), the convergence criteria can be set as:

$\max _{(i, j)} \cdot \operatorname{err}(f, i, j) \leq 10^{-6}$

\section{Results and discussion}

The Nusselt number distribution over the heated wall, as well as streamlines and isotherms within the inclined cavity, were investigated and discussed, according the external and internal Rayleigh. 192 tests have been done in this study. Initially the code's results were validated for many cases, with and without internal heat generation.

For the case of natural convection in a square cavity without internal heat generation, the results were compared with the results obtained from Davis [23], Shu and Xue [24], and Lo et al. [14], which simulated with different cases of grid size. In this case, $R a_{I}=0$ and $A R=1$ and external Rayleigh number $R a_{E}=10^{3}$ to $10^{6}$. The results showed a good agreement, as presented in Table 2 , where average Nusselt number compared with the results obtained from Davis [23] and showed low error. Also, this table shows the high efficiency for the DQ method in engineering applications, where it needs a lower number of grids points, which leads to reduced CPU time to get accurate smooth results. The other case is the differentially heated cavity with internal heat generation, and with validation done by Shim and Hyun [25], Oztop and Bilgen [17], and Islam et al. [26]. The code results also showed acceptable agreement with other results; see Table 3. Obviously, the code results were close to the results obtained from Islam et al. [26], where the partial differential equations solved the governing equations using finite element method, which has nearly the same discretized shape with the DQ method. Also, Figure 3 demonstrates the streamlines and isotherm contours in the cavity for $R a_{E}=10^{5}$ and $R a_{I}=10^{7}$ and compares them with Shim and Hyun [25], obtaining an acceptable agreement. Other cases included the effect of increasing of internal Rayleigh number in the cavity, as in case $2\left(R a_{I}=R a_{E}\right)$, case $3\left(R a_{I}=\right.$ $\left.10 R a_{E}\right)$, and case $4\left(R a_{I}=100 R a_{E}\right)$, for different aspect ratios and inclination angles of the cavity.

Shim and Hyun [25]

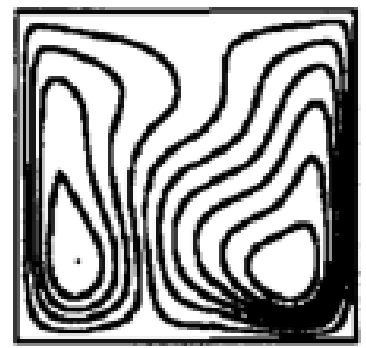

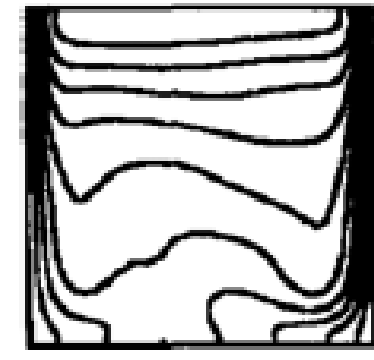

Current results
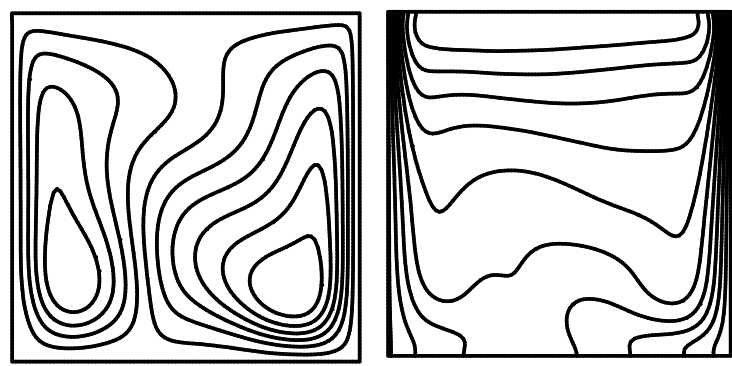

Figure 3 Comparison of streamlines and isotherms for validation test with internal heat generation, $R a_{E}=10^{5}$ and $R a_{I}=10^{7}$.

\section{DQ method efficiency}

The DQ method is based on from the idea of integral quadrature, and the key to this method is to determine the weighting coefficients for the discretization of a derivative of any order. For most engineering applications, numerical simulations can be completed using low order finite difference, finite element, and finite volume methods, with large numbers of grid points. To achieve an acceptable accuracy, low order method still requires the use of large numbers of grids points to obtain an accurate solution at these specified points. As a result, high order methods, such as the DQ method, can provide accurate numerical solutions with a small number of grid points. Tables $\mathbf{2}-\mathbf{5}$ show the efficiency of the 
DQ method according to the values of errors, CPU time, and grid points in the physical cavity comparing it with the other researchers; also, Figure 3 shows accurate results with smooth behaviour of numerical results using few grid points. From these results, we could see the importance of this method in engineering applications. For flow and thermal fields, Figures 4 - 6 show the streamlines and isothermal contours in the cavity for different inclination angles $(\gamma=0,30,45$, and 60), fixed external Rayleigh number $\left(R a_{E}=10^{5}\right)$ and different internal Rayleigh numbers $\left(R a_{I}=10^{5}, 10^{6}\right.$, and $\left.10^{7}\right)$.

Figure 4 demonstrates the inclination angle effect of the cavity where the flow strength is at $=0$, and if inclination angle increase is weaker according to the values of streamlines in the figure. In the hot and cold walls, the temperature maps are very close comparing with the other sides, because greater temperature gradients are seen only at these regions. This phenomenon could decrease with increase of the inclination angle of the cavity, where the other sides of cavity are kept adiabatic and the temperature contours are always normal to these sides, as observed in the figure. If internal Rayleigh number increases, the big vortex in the cavity will be divided into 2 vortices, as shown in Figures $\mathbf{5}$ and $\mathbf{6}$. In Figure 5, the large vortex exists on the right side of the cavity near to the cold wall, and another vortex with a weak strength exists near the hot wall, where it becomes large when increasing the inclination angle of the cavity. In this case, the streamlines and isotherms suffer from more influence of the $R a_{I}$. The whole cavity is occupied by 2 recirculation vortices in different angular directions near the side walls due to the buoyancy effect. Isotherms contours become irregular and distributed in the cavity due to differential heated and internal heat source.

For a high internal generation case, as in Figure 7, the 2 cells in the cavity have an irregular shape and streamlines are deformed according to the value of $R a_{I}$; also, increasing $\gamma$ leads to change in the strength of vortices in the cavity due to change in buoyancy force values. Isotherms change too, according to change in streamlines. Figures 7 - 9 show the influence of aspect ratio of the cavity on the flow and thermal fields at $R a_{I}=10^{5}, R a_{E}=10^{4}$, where the flow becomes strong and isotherms are distributed vertically at $\mathrm{AR}=2$, as shown in Figure 8, due to the hot wall becoming near to the cold side comparing with the other figures. Finally, Figure 10 presents the distribution of the average Nusselt number on vertical sections in the cavity for different cases of inclination angles and internal Rayleigh number. In all tests, increase in $\gamma$ value leads to decrease in the values of Nusselt number due to dissipation in the gravity force, while increase in $R a_{I}$ value leads to increase in the Nusselt number.

Table 2 Validation case for natural convection in differentially heated square cavity $\mathrm{AR}=1 . R a_{I}=0$.

\begin{tabular}{|c|c|c|c|c|c|c|c|c|}
\hline \multicolumn{9}{|c|}{$R a_{E}=10^{3}$} \\
\hline Grid size & $\begin{array}{c}7 \times 7 \\
\text { Present } \\
\text { results }\end{array}$ & $\begin{array}{c}7 \times 7 \\
\text { Shu and } \\
\text { Xue } \\
{[24]}\end{array}$ & $\begin{array}{c}9 \times 9 \\
\text { Present } \\
\text { results }\end{array}$ & $\begin{array}{c}9 \times 9 \\
\text { Shu and } \\
\text { Xue } \\
{[24]}\end{array}$ & $\begin{array}{c}13 \times 13 \\
\text { Present } \\
\text { results }\end{array}$ & $\begin{array}{c}13 \times 13 \\
\text { Shu and } \\
\text { Xue } \\
{[24]}\end{array}$ & $\begin{array}{c}21 \times 21 \\
\text { Lo et al. } \\
\quad[14]\end{array}$ & $\begin{array}{c}81 \times 81 \\
\text { Davis } \\
{[23]}\end{array}$ \\
\hline$N u_{o}$ & 1.118 & 1.10 & 1.118 & 1.117 & 1.118 & 1.118 & & 1.117 \\
\hline$N u_{\max }$ & 1.494 & 1.495 & 1.493 & 1.505 & 1.502 & 1.506 & & 1.505 \\
\hline$Y_{\text {location }}$ & 1.00 & 1.00 & 1.00 & 1.00 & 1.00 & 1.00 & & 1.00 \\
\hline$N u_{\text {mid }}$ & 1.113 & 1.21 & 1.114 & 1.117 & 1.117 & 1.118 & & 1.118 \\
\hline$N u_{a v g}$ & 1.113 & 1.123 & 1.115 & 1.118 & 1.117 & 1.118 & 1.118 & 1.118 \\
\hline$U_{\max }$ & 3.587 & 3.669 & 3.587 & 3.66 & 3.633 & 3.649 & & 3.649 \\
\hline$Y_{\text {location }}$ & 0.810 & 0.810 & 0.810 & 0.815 & 0.812 & 0.815 & & 0.813 \\
\hline CPU Time (s) & 5.0 & & 65 & & 173 & & & \\
\hline
\end{tabular}




\begin{tabular}{|c|c|c|c|c|c|c|c|c|c|}
\hline \multicolumn{10}{|c|}{$R a_{E}=10^{4}$} \\
\hline Grid size & $\begin{array}{c}9 \times 9 \\
\text { Present } \\
\text { results }\end{array}$ & $\begin{array}{l}9 \times 9 \\
\text { Shu } \\
\text { and } \\
\text { Xue } \\
{[24]}\end{array}$ & $\begin{array}{c}13 \times 13 \\
\text { Present } \\
\text { results }\end{array}$ & $\begin{array}{c}13 \times 13 \\
\text { Shu and } \\
\text { Xue } \\
{[24]}\end{array}$ & $\begin{array}{c}15 \times 15 \\
\text { Present } \\
\text { results }\end{array}$ & $\begin{array}{c}15 \times 15 \\
\text { Shu and } \\
\text { Xue } \\
{[24]}\end{array}$ & $\begin{array}{c}21 \times 21 \\
\text { Present } \\
\text { results }\end{array}$ & $\begin{array}{c}21 \times 21 \\
\text { Lo et al. } \\
{[14]}\end{array}$ & $\begin{array}{c}81 \times 81 \\
\text { Davis } \\
{[23]}\end{array}$ \\
\hline$N u_{o}$ & 2.129 & 2.07 & 2.268 & 2.262 & 2.250 & 2.248 & 2.244 & & 2.238 \\
\hline$N u_{\max }$ & 3.151 & 3.18 & 3.562 & 3.571 & 3.539 & 3.543 & 3.528 & & 3.528 \\
\hline$Y_{\text {location }}$ & 0.100 & 0.09 & 0.150 & 0.15 & 0.14 & 0.145 & 0.14 & & 0.14 \\
\hline$N u_{\min }$ & 0.708 & 0.65 & 0.586 & 0.586 & 0.593 & 0.586 & 0.587 & & 0.586 \\
\hline$Y_{\text {location }}$ & 1.00 & 1.00 & 1.00 & 1.00 & 1.00 & 1.00 & 1.00 & & 1.00 \\
\hline$N u_{m i d}$ & 2.168 & 2.20 & 2.241 & 2.250 & 2.240 & 2.245 & 2.243 & & 2.243 \\
\hline$N u_{a v g}$ & 2.164 & 2.21 & 2.239 & 2.249 & 2.239 & 2.245 & 2.243 & 2.244 & 2.243 \\
\hline$U_{\max }$ & 15.82 & 15.9 & 16.17 & 16.189 & 16.18 & 16.19 & 16.19 & & 16.178 \\
\hline$Y_{\text {location }}$ & 0.82 & 0.82 & 0.822 & 0.825 & 0.82 & 0.825 & 0.82 & & 0.823 \\
\hline$V_{\max }$ & 17.49 & 18.9 & 19.66 & 19.668 & 19.67 & 19.638 & 19.65 & & 19.617 \\
\hline$X_{\text {location }}$ & 0.11 & 0.11 & 0.12 & 0.120 & 0.120 & 0.120 & 0.12 & & 0.119 \\
\hline Error \% & -3.5 & -1.2 & -0.17 & 0.26 & -0.17 & 0.089 & 0.0 & 0.044 & 0.0 \\
\hline CPU Time (s) & 53 & & 133 & & 215 & & 724 & 120 & \\
\hline
\end{tabular}

\begin{tabular}{|c|c|c|c|c|c|}
\hline \multicolumn{6}{|c|}{$R a_{E}=10^{5}$} \\
\hline Grid size & $\begin{array}{c}21 \times 21 \\
\text { Present results }\end{array}$ & $\begin{array}{c}21 \times 21 \\
\text { Lo et al. }[14]\end{array}$ & $\begin{array}{c}25 \times 25 \\
\text { Present results }\end{array}$ & $\begin{array}{c}25 \times 25 \\
\text { Lo et al. }[14]\end{array}$ & $\begin{array}{c}81 \times 81 \\
\text { Davis [23] }\end{array}$ \\
\hline$N u_{o}$ & 4.5307 & & 4.52 & & 4.509 \\
\hline$N u_{\max }$ & 7.7802 & & 7.704 & & 7.717 \\
\hline$Y_{\text {location }}$ & 0.080 & & 0.08 & & 0.081 \\
\hline$N u_{\min }$ & 0.7381 & & 0.732 & & 0.729 \\
\hline$Y_{\text {location }}$ & 1.00 & & 1.00 & & 1.00 \\
\hline $\mathrm{Nu}_{\text {mid }}$ & 4.512 & & 4.516 & & 4.519 \\
\hline$N u_{a v g}$ & 4.511 & 4.520 & 4.515 & 4.521 & 4.519 \\
\hline$U_{\max }$ & 35.261 & & 35.22 & & 34.73 \\
\hline$Y_{\text {location }}$ & 0.86 & & 0.86 & & 0.855 \\
\hline$V_{\max }$ & 68.38 & & 68.29 & & 68.59 \\
\hline$X_{\text {location }}$ & 0.07 & & 0.07 & & 0.066 \\
\hline Error \% & -0.177 & 0.022 & -0.088 & 0.044 & 0.0 \\
\hline CPU Tim (s) & 517 & & 993 & & \\
\hline
\end{tabular}

\begin{tabular}{|c|c|c|c|c|c|}
\hline \multicolumn{6}{|c|}{$R a_{E}=10^{6}$} \\
\hline Grid size & $\begin{array}{c}25 \times 25 \\
\text { Present results }\end{array}$ & $\begin{array}{c}25 \times 25 \\
\text { Lo et al. }[14]\end{array}$ & $\begin{array}{c}31 \times 31 \\
\text { Present results }\end{array}$ & $\begin{array}{c}31 \times 31 \\
\text { Lo et al. }[14]\end{array}$ & $\begin{array}{c}81 \times 81 \\
\text { Davis [23] }\end{array}$ \\
\hline$N u_{o}$ & 8.919 & & 8.819 & & 8.817 \\
\hline$N u_{\max }$ & 17.66 & & 17.66 & & 17.925 \\
\hline$Y_{\text {location }}$ & 0.05 & & 0.04 & & 0.038 \\
\hline$N u_{\min }$ & 0.924 & & 0.974 & & 0.989 \\
\hline$Y_{\text {location }}$ & 1.00 & & 1.00 & & 1.00 \\
\hline$N u_{\text {mid }}$ & 8.83 & & 8.797 & & 8.799 \\
\hline$N u_{a v g}$ & 8.824 & 8.823 & 8.82 & 8.823 & 8.80 \\
\hline$U_{\max }$ & 65.13 & & 64.83 & & 64.63 \\
\hline$Y_{\text {location }}$ & 0.85 & & 0.850 & & 0.850 \\
\hline$V_{\max }$ & 220.99 & & 220.02 & & 219.36 \\
\hline$X_{\text {location }}$ & 0.04 & & 0.39 & & 0.038 \\
\hline Error \% & 0.27 & 0.26 & 0.22 & 0.26 & 0.0 \\
\hline CPU Time (s) & 669 & & 1365 & & \\
\hline
\end{tabular}


http://wjst.wu.ac.th

Table 3 Average Nusselt number on the hot wall and CPU time for validation test with $R a_{I}$.

\begin{tabular}{|c|c|c|c|c|c|}
\hline \multicolumn{6}{|c|}{$N u_{o}$} \\
\hline$R a_{I}$ & $R a_{E}$ & $\begin{array}{c}\text { Shim and Hyun } \\
{[25]}\end{array}$ & $\begin{array}{c}\text { Oztop and Bilgen } \\
{[17]}\end{array}$ & Islam et al. [26] & Present \\
\hline $10^{6}$ & $10^{5}$ & -0.01 & +0.1 & -0.1 & $-0.097(40 \mathrm{~s})$ \\
\hline $10^{7}$ & $10^{5}$ & -66.0 & -59.0 & -43.02 & $-42.89(23 \mathrm{~s})$ \\
\hline
\end{tabular}

Table 4 Average Nusselt number through the cavity and CPU time for different cases.

\begin{tabular}{|c|c|c|c|c|}
\hline \multirow{3}{*}{ AR } & \multicolumn{4}{|c|}{$R a_{E}=10^{5}$} \\
\hline & \multicolumn{4}{|c|}{$\begin{array}{l}\text { Inclined angle } \gamma \\
\text { Case } 2, R a_{I}=R a_{E}\end{array}$} \\
\hline & $0^{\mathbf{0}}$ & $30^{\circ}$ & $45^{\circ}$ & $60^{\circ}$ \\
\hline 0.5 & $11.0398(96 \mathrm{~s})$ & $3.9394(170 \mathrm{~s})$ & $2.1862(231 \mathrm{~s})$ & $1.4318(379 \mathrm{~s})$ \\
\hline 1. & $5.9545(47 \mathrm{~s})$ & $3.8529(55 \mathrm{~s})$ & $2.4581(63 \mathrm{~s})$ & $1.5341(81 \mathrm{~s})$ \\
\hline 2. & $11.2801(58 \mathrm{~s})$ & $9.1776(63 \mathrm{~s})$ & $7.2388(64 \mathrm{~s})$ & $4.6897(71 \mathrm{~s})$ \\
\hline \multicolumn{5}{|c|}{ Case $3, R a_{I}=10 \times R a_{E}$} \\
\hline & $\mathbf{0}^{\mathbf{0}}$ & $30^{\circ}$ & $45^{\circ}$ & $60^{\circ}$ \\
\hline 0.5 & $14.7162(74 \mathrm{~s})$ & $0.9143(99 \mathrm{~s})$ & $-3.2941(105 \mathrm{~s})$ & $-6.3799(137 \mathrm{~s})$ \\
\hline 1. & $6.4921(40 \mathrm{~s})$ & $3.6271(50 \mathrm{~s})$ & $2.1897(59 \mathrm{~s})$ & $1.1598(68 \mathrm{~s})$ \\
\hline 2. & $11.8397(37 \mathrm{~s})$ & $8.7486(53 \mathrm{~s})$ & $6.3765(55 \mathrm{~s})$ & $3.6780(57 \mathrm{~s})$ \\
\hline \multicolumn{5}{|c|}{ Case 4, $R a_{I}=100 \times R a_{E}$} \\
\hline & $\mathbf{0}^{\mathbf{o}}$ & $30^{\circ}$ & $45^{\circ}$ & $60^{\circ}$ \\
\hline 0.5 & $12.5709(39 \mathrm{~s})$ & $-79.4248(64 \mathrm{~s})$ & $-86.4323(97 \mathrm{~s})$ & $-116.6522(127 \mathrm{~s})$ \\
\hline 1. & $9.4914(23 \mathrm{~s})$ & $-8.3285(28 \mathrm{~s})$ & $-12.8035(33 \mathrm{~s})$ & $-17.2101(42 \mathrm{~s})$ \\
\hline 2. & $18.3061(28 \mathrm{~s})$ & $-7.2574(28 \mathrm{~s})$ & $-17.9709(30 \mathrm{~s})$ & $-27.8529(37 \mathrm{~s})$ \\
\hline
\end{tabular}

Table 5 Average Nusselt number on the hot wall at $\mathbf{R a}_{\mathbf{E}}=\mathbf{1 0}^{\mathbf{3}}, \mathrm{AR}=1$.

\begin{tabular}{ccccc}
\hline & \multicolumn{5}{c}{$\boldsymbol{N u}_{\boldsymbol{o}}$} \\
\hline $\boldsymbol{R a}_{\boldsymbol{I}}$ & \multicolumn{4}{c}{ Inclined angle $\boldsymbol{\gamma}$} \\
\cline { 2 - 6 } $\mathbf{1 0}^{\mathbf{4}}$ & $\mathbf{0}^{\mathbf{0}}$ & $\mathbf{3 0}^{\mathbf{0}}$ & $\mathbf{4 5}^{\mathbf{0}}$ & $\mathbf{6 0}^{\mathbf{0}}$ \\
$\mathbf{1 0}^{\mathbf{5}}$ & -3.754 & -3.865 & -3.920 & -3.963 \\
$\mathbf{1 0}^{\mathbf{6}}$ & -47.301 & -52.6392 & -54.583 & -55.459 \\
\end{tabular}



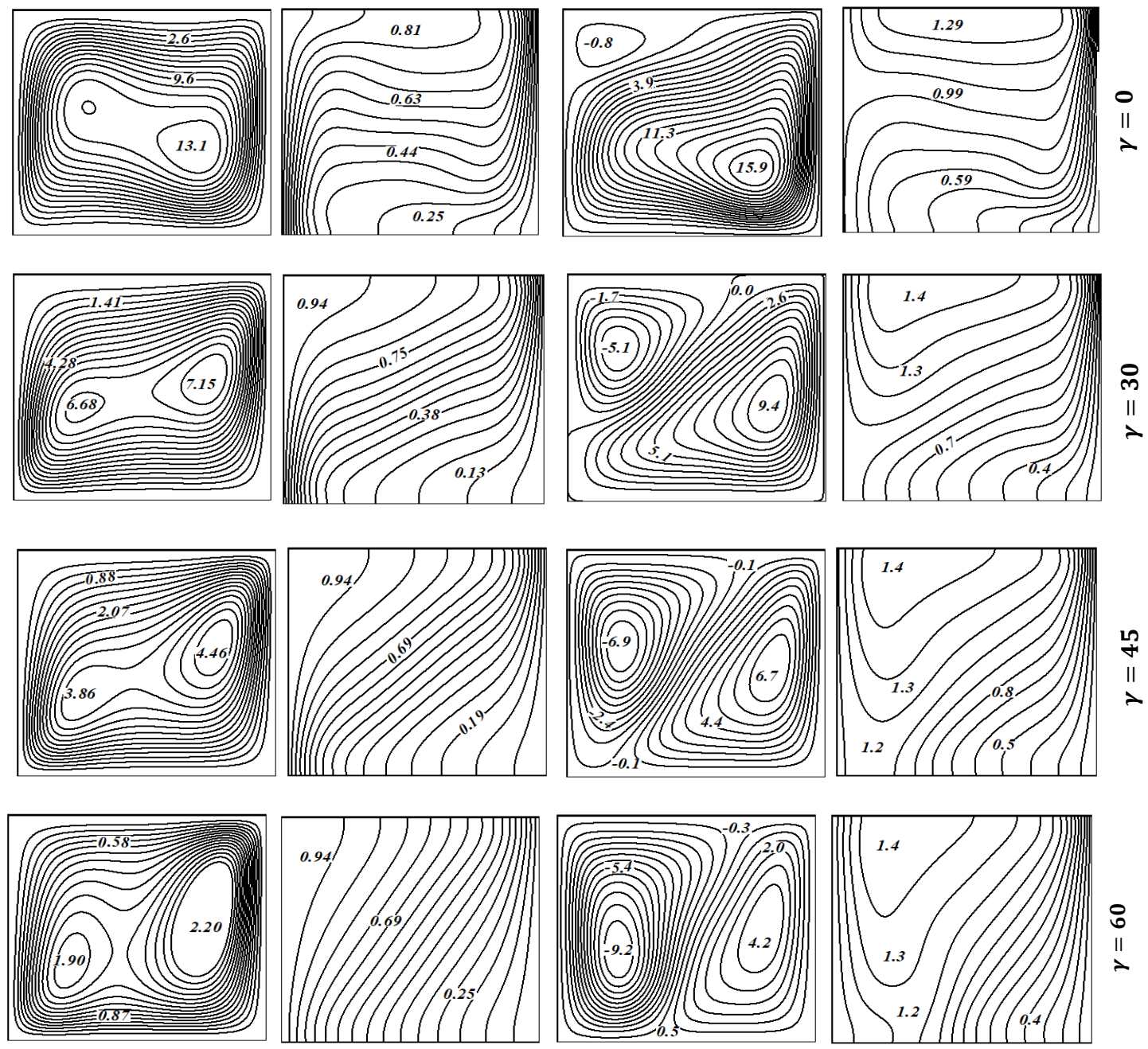

Figure 4 Streamlines and isotherms in the cavity

Figure 5 Streamlines and isotherms in the cavity for Case 2, $R a_{I}=R a_{E}=10^{5}$ at $\mathrm{AR}=1$. for Case 3, $\mathrm{Ra}_{\mathrm{I}}=10^{6}, \mathrm{Ra}_{\mathrm{E}}=10^{5}$ at $\mathrm{AR}=1$. 
$\gamma=0$
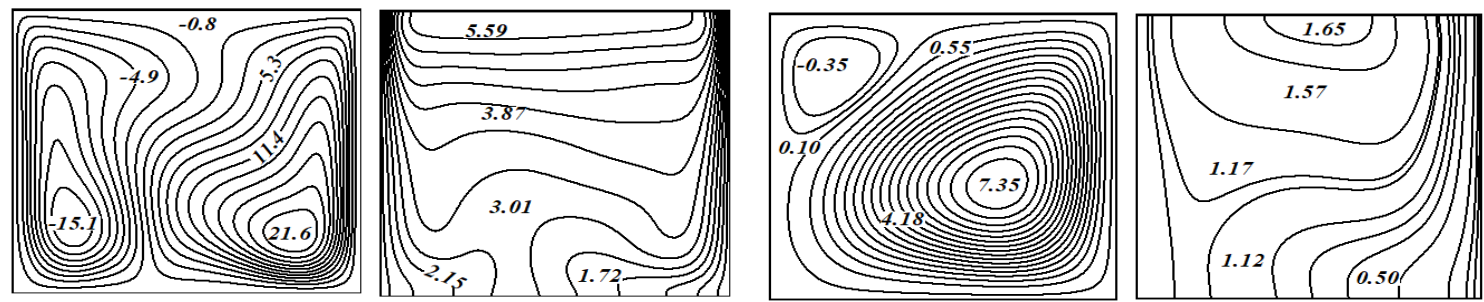

$\gamma=30$
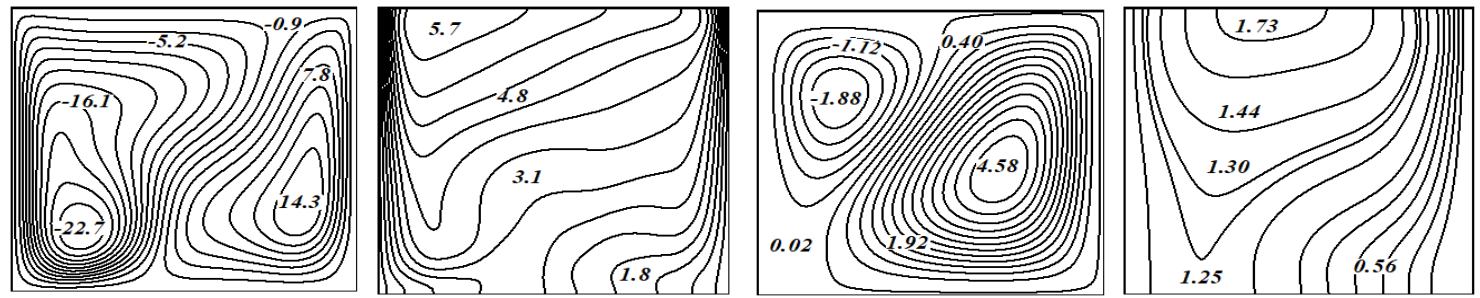

$\gamma=45$
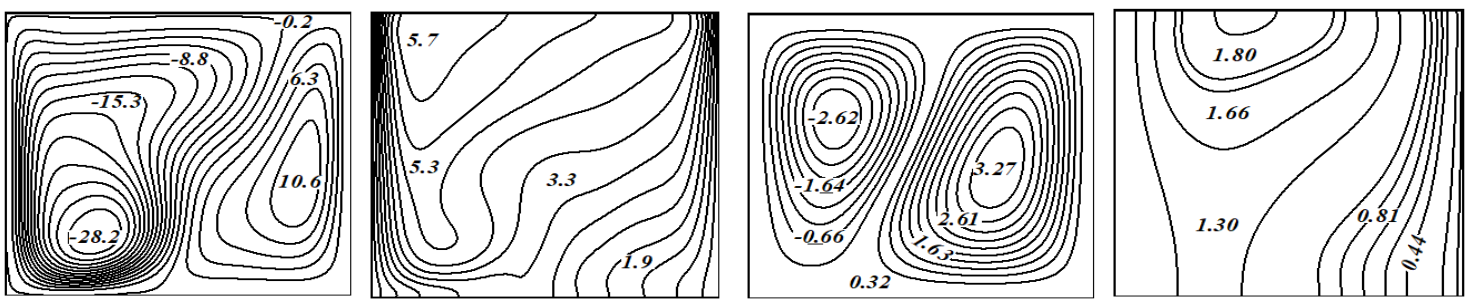

$\gamma=60$
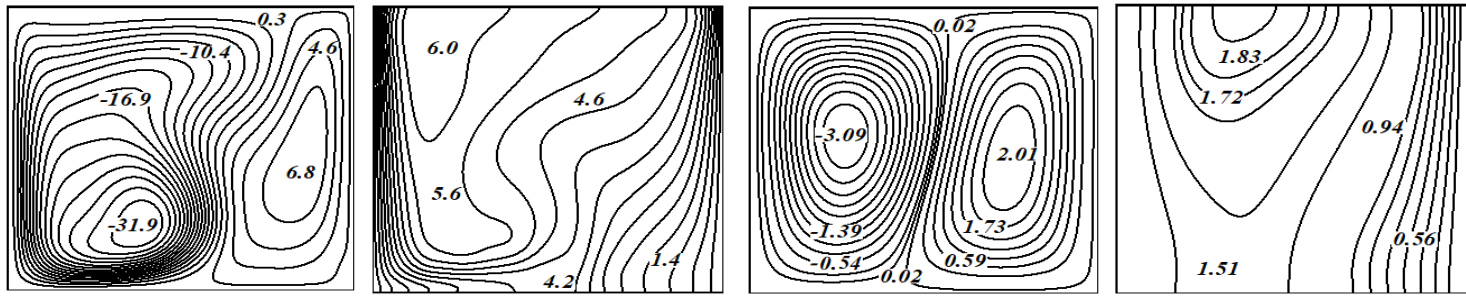

Figure 6 Streamlines, and isotherms in the cavity for Case $4, R a_{I}=10^{7}, R a_{E}=10^{5}$ at $\mathrm{AR}$ $=1$.
Figure 7 Streamlines, and isotherms in the cavity for Case $3, R a_{I}=10^{5}, R a_{E}=10^{4}$ at $\mathrm{AR}$ $=1$. 
$\gamma=0$
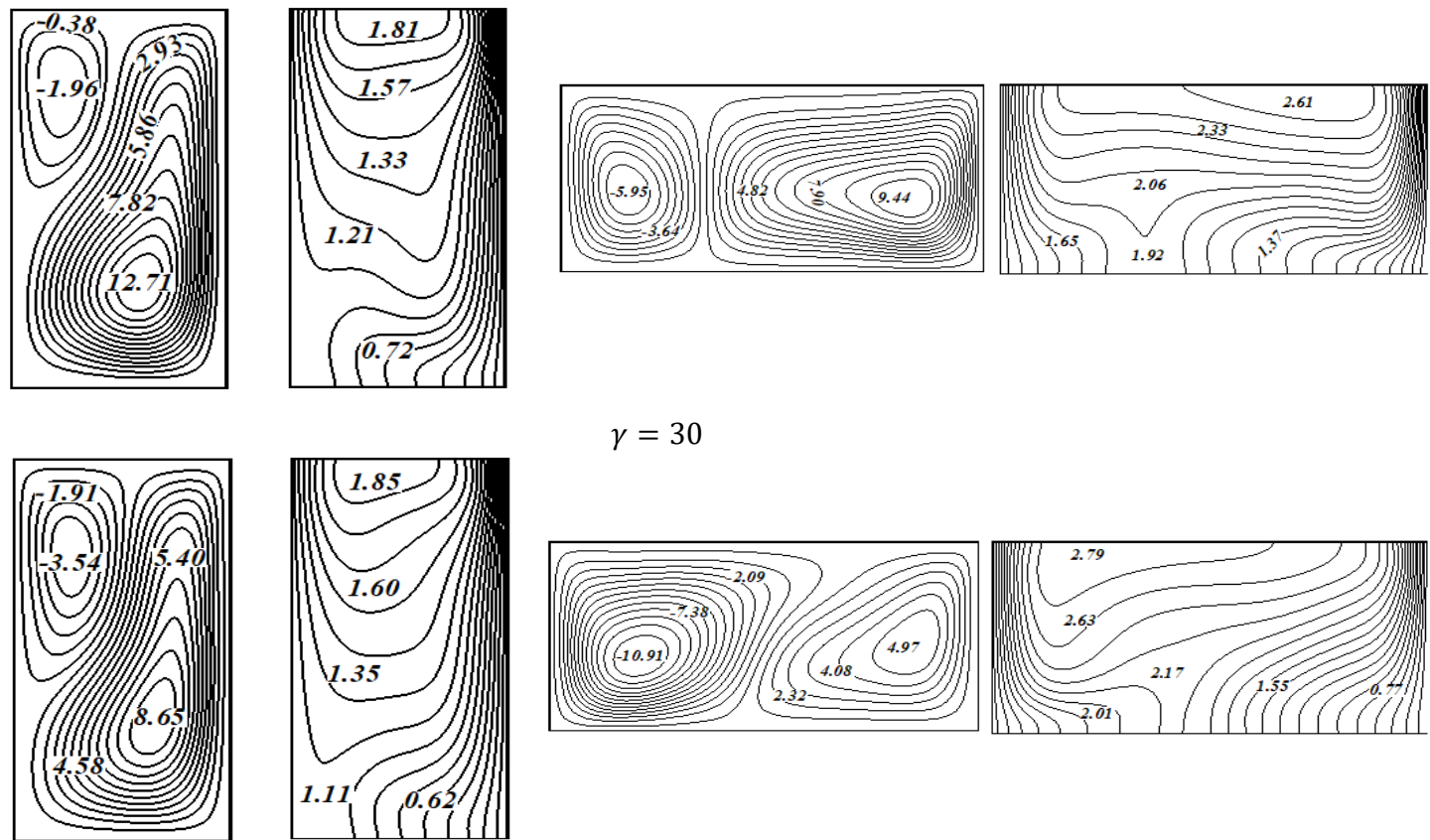

$\gamma=30$
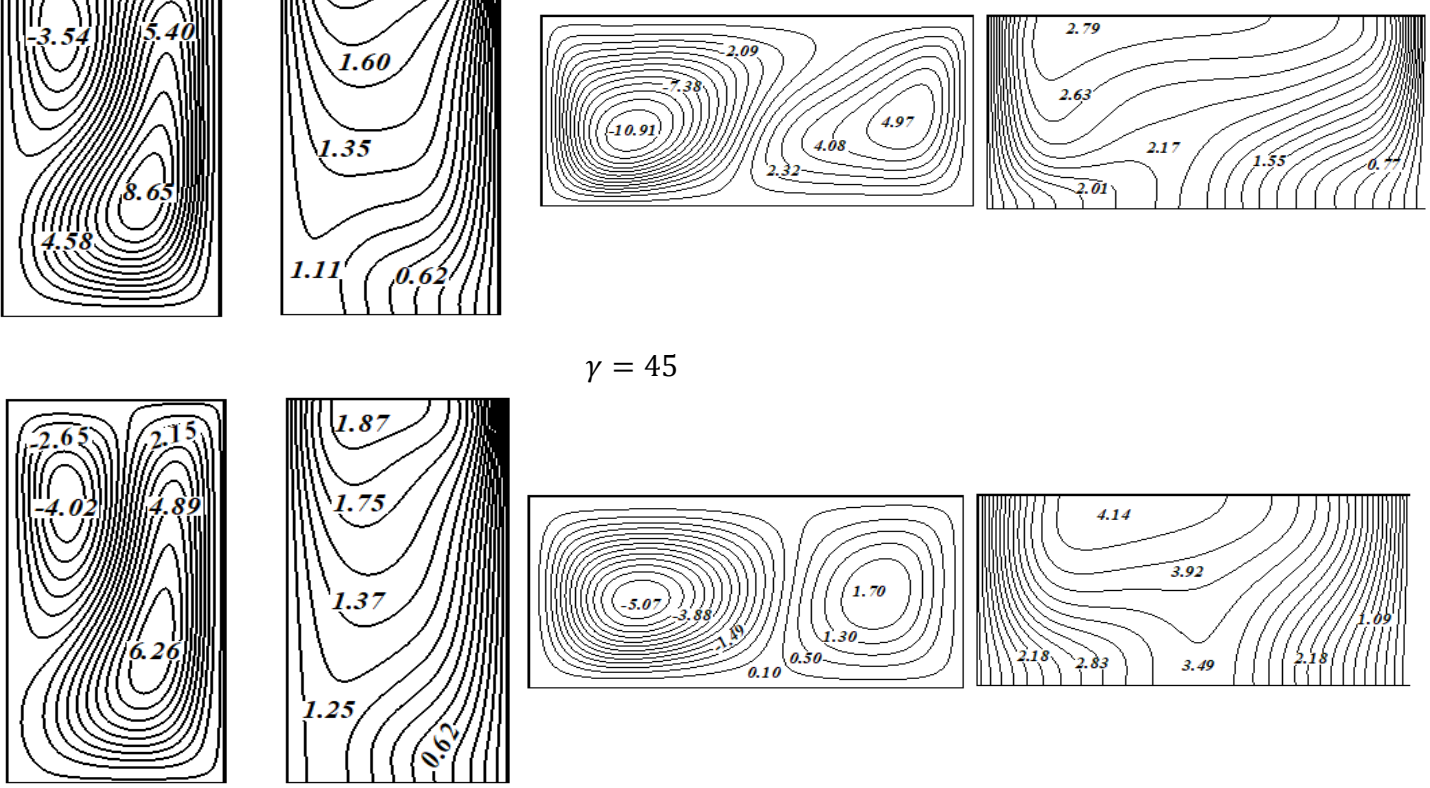

$$
\gamma=45
$$
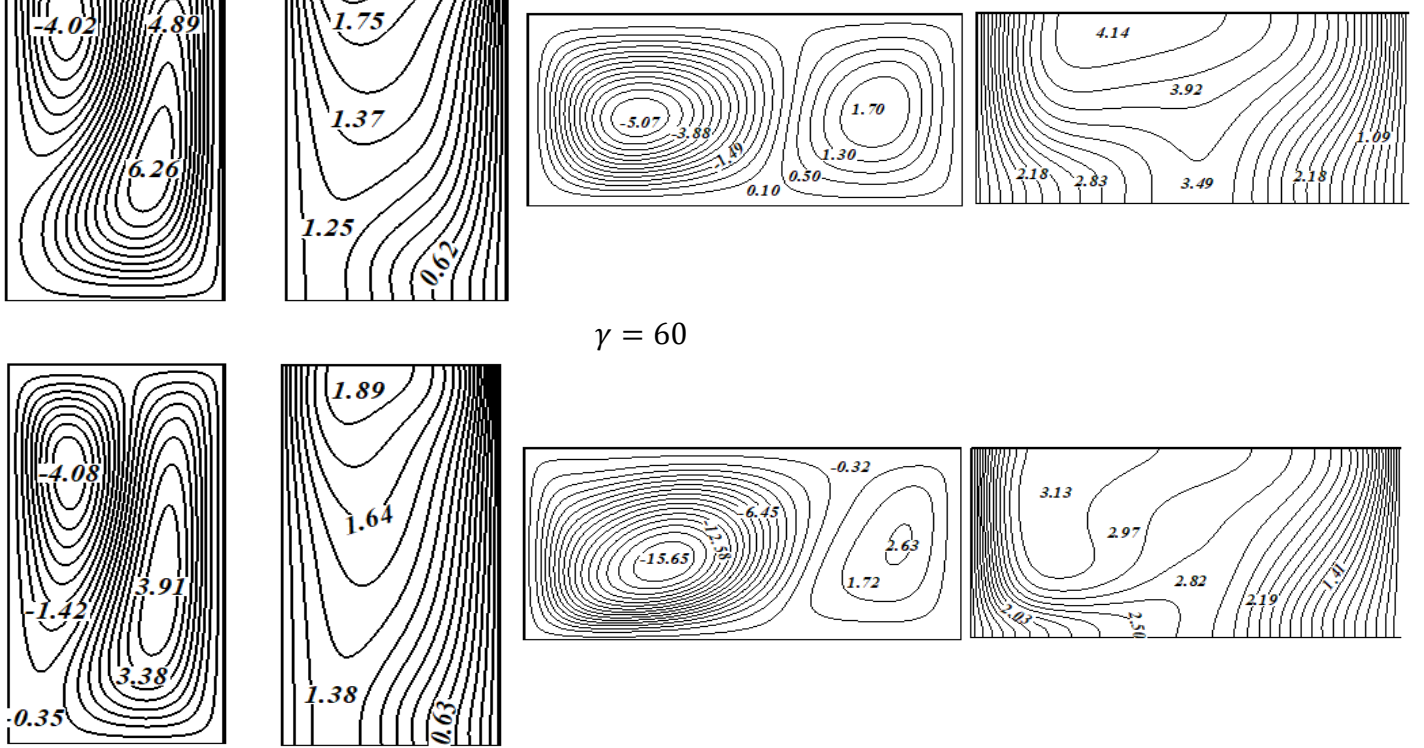

$$
\gamma=60
$$
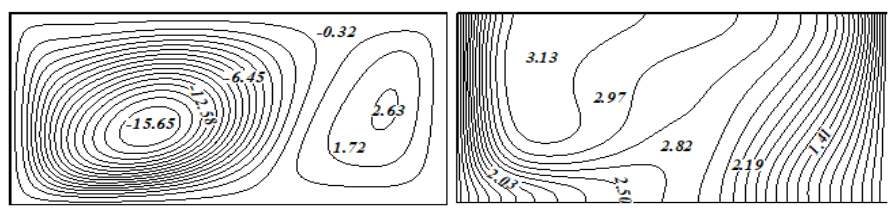

Figure 8 Streamlines and isotherms

Figure 9 Streamlines and isotherms in the cavity for Case in the cavity for Case $3, R a_{I}=$ $10^{5}, R a_{E}=10^{4}$ at $\mathrm{AR}=2$.

$3, R a_{I}=10^{5}, R a_{E}=10^{4}$ at $\mathrm{AR}=0.5$. 

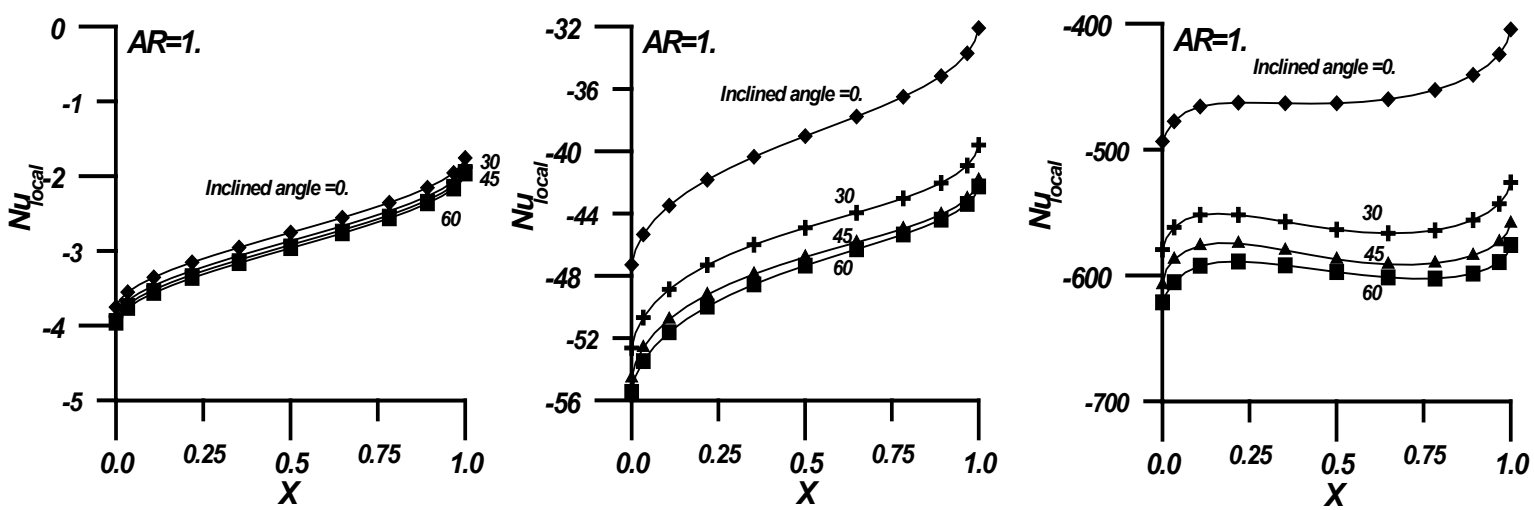

Figure 10 Average Nusselt number on vertical line in the cavity for Case 4, $R a_{E}=10^{3}, R a_{I}=$ $10^{4}(\mathrm{~A}), 10^{5}(\mathrm{~B})$, and $10^{6}(\mathrm{C})$ at $\mathrm{AR}=1$.

\section{Conclusions}

Natural laminar convective fluid flow has been simulated inside inclined rectangular cavities with and without internal heat generation for different aspect ratios and inclination angles. Results concluded that:

1) It was found that, when compared to the benchmark solution for the test problem, accurate numerical results can be obtained by the present method using fewer grid points and shorter CPU time for calculation.

2) Increased $R a_{I}$ leads to increasing heat transfer rate and its direction out from the cavity at both hot and cold walls.

3) Average Nusselt number in the cavity was very sensitive to the values of AR, $\gamma, R a_{E}$, and $R a_{I}$.

4) For lower values of $R a_{I}$, heat transfer diffusion is more prominent, while for higher values of $R a_{I}$, convection outweighs diffusion.

5) We recommended using the DQ method for 2-D laminar flow heat transfer application.

6) It is possible to expand the presented differential quadrature approach to solve a 3-dimensional flow in the future, or for all convection modes.

\section{References}

[1] AS Kuesters and AW Woods. A comparison of winter heating demand using a distributed and a point source of heating with mixing ventilation. Energ. Build. 2012; 55, 332-40.

[2] S Wang, Z Shen and L Gu. Numerical simulation of buoyancy-driven turbulent ventilation in attic space under winter conditions. Energ. Build. 2012; 47, 360-8.

[3] PT Tsilingiris. Combined heat and mass transfer analyses in solar distillation systems- The restrictive conditions and a validity range investigation. Sol. Energ. 2012; 86, 3288-300.

[4] D Liu, FY Zhao and HQ Wang. Passive heat and moisture removal from a natural vented enclosure with a massive wall. Energy 2011; 36, 2867-82.

[5] SKS Boetcher, FA Kulacki and JH Davidson. Use of a shroud and baffle to improve natural convection to immersed heat exchangers. J. Sol. Energ. Eng. 2012; 134, 011010.

[6] A Mezrhab, L Elfarh, H Naji and D Lemonnier. Computation of surface radiation and natural convection in a heated horticultural greenhouse. Appl. Energ. 2010; 87, 894-900.

[7] $\mathrm{H}$ Singh and PC Eames. Correlations for natural convective heat exchange in CPC solar collector cavities determined from experimental measurements. Sol. Energ. 2012; 86, 2443-57.

[8] JC DeBlois, MM Bilec and LA Schaefer. Design and zonal building energy modelling of a roof integrated solar chimney. Renew. Energ. 2013; 52, 241-50. 
http://wjst.wu.ac.th

[9] A Bairi, JMG de Maria, I Bairi, $\mathrm{N}$ Laraqi, E Zarco-Pernia and $\mathrm{N}$ Alilat. 2D transient natural convection in diode cavities containing an electronic equipment with discrete active bands under constant heat flux. Int. J. Heat Mass Transf. 2012; 55, 4970-80.

[10] YS Tseng, CH Lin, YR Yuann, JR Wang and FP Tsai. Analysing the alternative shutdown cooling behaviours for Chinshan nuclear power plant using CFD simulation. Ann. Nucl. Energ. 2011; 38, 2557-68.

[11] R Bellman, BG Kashef and J Casti. Differential quadrature: A technique for the rapid solution of nonlinear partial differential equations. J. Comput. Phys. 1972; 10, 40-52.

[12] C Shu and BE Richards. Application of generalized differential quadrature to solve two-dimensional incompressible Navier-Stokes equations. Int. J. Numer. Meth. Fluids 1992; 15, 791-8.

[13] C Shu. Differential quadrature and its application in engineering. Springer, London, 2000.

[14] DC Lo, DL Young, K Murugesan, CC Tsai and MH Gou. Velocity-vorticity formulation for 3D natural convection in an inclined cavity by DQ method. Int. J. Heat Mass Transf. 2007; 50, 479-91.

[15] DC Lo, DL Young and K Murugesan. GDQ method for natural convection in a cubic cavity using velocity-vorticity formulation. Numer. Heat TR B-Fund. 2005; 48, 363-86.

[16] M Rahman and MAR Sharif. Numerical study of laminar natural convection in inclined rectangular enclosures for various aspect ratios. Numer. Heat TR A-Appl. 2003; 44, 355-73.

[17] H Oztop and E Bilgen. Natural convection in differentially heated and partially divided square cavities with internal heat generation. Int. J. Heat Fluid Flow 2006; 27, 466-75.

[18] M Boukendil, LE Moutaouakil, Z Zrikem and A Abdelbaki. Natural convection and surface radiation in an insulated square cavity with inner hot and cold square bodies. Mater. Today 2021. DOI:10.1016/j.matpr.2020.12.1011.

[19] S Aljabair, AA Mohammed and I Alesbe. Natural convection heat transfer in corrugated annuli with $\mathrm{H}_{2} \mathrm{OAl}_{2} \mathrm{O}_{3}$ nanofluid. Heliyon 2020; 6, e05568.

[20] A Fabregat and J Pallarès. Heat transfer and boundary layer analyses of laminar and turbulent natural convection in a cubical cavity with differently heated opposed walls. Int. J. Heat Mass Transf. 2020; 151, 119409.

[21] R Hidki, LE Moutaouakil, Z Charqui, M Boukendil and Z Zrikem. Natural convection in a square cavity containing two heat-generating cylinders with different geometries. Mater. Today 2021. DOI:10.1016/j.matpr.2021.01.626.

[22] YO El-Dib and GM Moatimid. Stability configuration of a rocking rigid rod over a circular surface using the homotopy perturbation method and Laplace transform. Arab. J. Sci. Eng. 2019; 44, 658191.

[23] DGV Davis. Natural convection of air in a square cavity, a bench mark numerical solution. Int. J. Numer. Meth. Fluids 1983; 3, 249-64.

[24] C Shu and H Xue. Comparison of two approaches for implementer stream function boundary condition in DQ simulation of natural convection in a square cavity. Int. J. Heat Fluid Flow 1998; 19, 59-68.

[25] YM Shim and JM Hyun. Transient confined natural convection with internal heat generation. Int. J. Heat Fluid Flow 1997; 18, 328-33.

[26] T Islam, S Saha, M Arif, M Mamun and G Saha. Natural convection in an inclined square enclosure containing internal energy sources. J. Mech. Eng. 2007; 37, 24-32. 